\section{$\underset{\substack{\text { hommes } \\ \text { \& migrations }}}{ }$}

\section{Hommes \& migrations}

Revue française de référence sur les dynamiques

migratoires

\section{$1327 \mid 2019$}

Capitales européennes et diversité culturelle

\title{
Roubaix, une lumière
}

Film d'Arnaud Desplechin (France, 2019)

\section{Mouloud Mimoun}

\section{OpenEdition \\ 1 Journals}

\section{Édition électronique}

URL : https://journals.openedition.org/hommesmigrations/10500

DOI : 10.4000/hommesmigrations. 10500

ISSN : 2262-3353

\section{Éditeur}

Musée national de l'histoire de l'immigration

\section{Édition imprimée}

Date de publication : 1 octobre 2019

Pagination : 198-199

ISBN : 978-2-919040-47-6

ISSN : $1142-852 X$

Référence électronique

Mouloud Mimoun, "Roubaix, une lumière », Hommes \& migrations [En ligne], 1327 | 2019, mis en ligne le 01 octobre 2019, consulté le 08 janvier 2022. URL : http://journals.openedition.org/

hommesmigrations/10500; DOI : https://doi.org/10.4000/hommesmigrations.10500 


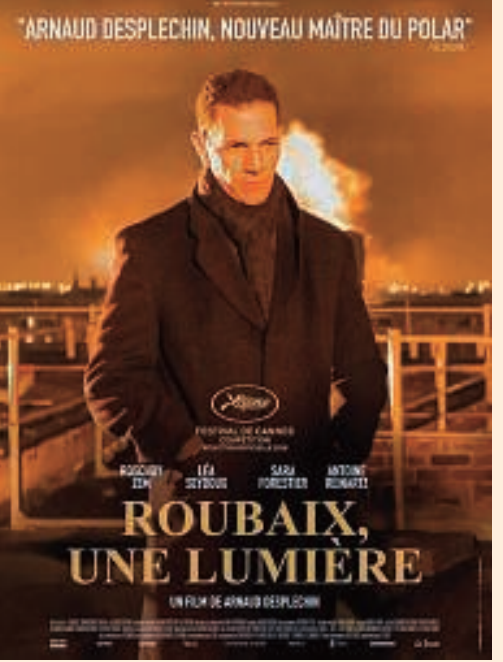

franco-marocain Roschdy Zem dans le 7 e art et l'audiovisuel français.

Il y a d'abord le cinquième long-métrage qu'il a mis en scène, Persona non grata, dans lequel il incarne une sorte de tueur à gages renouant avec ses premiers emplois, il y a 25 ans, quand il ne sortait pas des rôles de dealer ou de petite frappe auxquels étaient cantonnés les acteurs francomaghrébins issus des cités.

Et puis tout change. Dans Roubaix, une lumière d'Arnaud Desplechin, qui aurait pu prétendre à la Palme d'Or de Cannes 2019, il endosse «l'habit» d'un commissaire de police, Daoud, qui officie dans la ville où il a grandi, en l'occurrence Roubaix, ce Nord si cher à Desplechin qui s'y immerge avec une connaissance aigüe des lieux, de l'atmosphère des mentalités et du contexte social. Le récit donne à voir dans une première partie, le quotidien, fait de faits divers, d'un commissariat où convergent une voiture brûlée ou la fugue d'une jeune beurette franco-algérienne entre autres...

\section{Roubaix, une lumière}

Film d'Arnaud Desplechin (Franc,e 2019)

Incontestablement, l'année 2019, et plus particulièrement la rentrée de septembre, consacrent le talent et la place privilégiée qu'occupe désormais l'acteur réalisateur

L'intrigue centrale, elle, se noue sur un mode thriller autour de l'assassinat d'une vieille femme de 83 ans auquel est mêlé un couple féminin formé par Léa Seydoux (Claude) et Sara Forestier (Marie), toutes deux sorties d'un fait divers réel (traité sous forme de 
documentaire) et dont s'est inspiré fortement le réalisateur Arnaud Desplechin. Mais le rapport au réel prend fin ici pour emprunter les arcanes de la fiction.

Roschdy Zem survole le film... Au départ, il y a sa silhouette très élancée, son visage autant cabossé que marquant, sa démarche, son côté à la fois humaniste et taiseux qui débouchent sur ce qu'au cinéma on appelle la «présence». Une relation singulière s'établit entre Daoud et Louis (Antoine Reinartz), un collègue policier mal dans sa peau de catholique pas au clair.

Les scènes d'interrogatoire des deux jeunes coupables ne sont pas sans rappeler le naturalisme et le vérisme qui caractérisent Polisse de Maïwenn. Le spectateur n'est plus extérieur aux situations, il est en pleine immersion dans le réel. Et les différences d'approche des policiers, souvent dans l'excès et les cris, font écho à la force tranquille et humaine de Daoud, proche de la vraie personnalité de Roschdy Zem. Mais l'évènement audiovisuel sur lequel nous reviendrons, c'est certainement la série Les Sauvages à l'écran de Canal+ dès septembre (6 x 52 min) où Roschdy Zem incarne un candidat beur à la présidence de la République et qui constituera sans aucun doute un événement national qui interroge l'identité de la France et sa dimension multiculturelle...

Mouloud Mimoun 